\title{
Histological and Immunohistochemical Studies of Furstenberg's Rosette in Sheep and Goat
}

\author{
S. Senthilkumar ${ }^{1 *}$, T.A. Kannan ${ }^{1},{\text { Geetha } \text { Ramesh }^{1} \text { and D. Sumathi }}^{2}$ \\ ${ }^{1}$ Department of Veterinary Anatomy, Madras Veterinary College, Chennai, INDIA \\ ${ }^{2}$ Department. of Veterinary Clinical Medicine, Madras Veterinary College, Chennai, INDIA
}

"Corresponding author: S Senthilkumar; E-mail: senthilkumarvetpg@gmail.com

Received: 07 Dec., 2019

Revised: 27 Dec., 2019

Accepted: 25 Jan., 2020

\begin{abstract}
A total of twelve healthy adult Madras Red ewe and Boer local she-goat teats were histologically and immunohistochemically examined. In between the teat canal and teat cistern Furstenberg's rosette was appeared as modified zone of mucosa thrown into primary and secondary folds. The mucosal folds were lined by a bilayered cuboidal epithelium. Subepithelial area of rosette was composed of numerous lymphocytes, polymorphonuclear leukocytes, macrophages and plasma cells. Mucosa below the Furstenberg's rosette was lined by stratified squamous keratinized epithelium. Immunohistochemical staining of rosette by CD3 antibody revealed the localization of intraepithelial ' $\mathrm{T}$ ' lymphocytes in the mucosal folds. ' $\mathrm{T}$ ' lymphocytes were also localized in the lamina propria region.
\end{abstract}

Keywords: Madras Red ewe, Boer local she-goat, Furstenberg's rosette, histology, immnunohistochemistry

Teat is the primary route of entry of ascending infections by microorganisms that causes mastitis in mammary gland of ruminants. Apart from the natural protective barriers in the teat end such as keratin produces by teat canal epithelium and teat skin, there is a rosette like structure that comprises numerous antibody producing cells and phagocytes to fight entering antigens from the external environment.

In cows, at the union of teat cistern and teat canal, the double-layered epithelium of teat cistern, abruptly changed ventrally to stratified squamous epithelium of teat canal. This region is called Furstenberg's rosette (Nickerson and Akers, 2011). Under low magnification, examination of cross section of the teat sinus in cows reveals the epithelial folds, covering the closed teat canal resembling the petallike arrangement or rosette of a flower (Smolenski, 2018). There is a Furstenberg's rosette associated lymphoid tissue (FALT) in mammary gland of cow and antigens are received in this region. Specific response is formed locally against these antigens and has an important role in mucosal immune defense of teat end (Asti et al., 2011).
Furstenberg's rosette is acting less as mechanical seal of teat canal and more as a local immune cell defense. (Avdic et al., 2015).

Madras Red sheep (Ovis aries) breed characters, which is meat type breed, native to the Kanchipuram and Madras districts of Tamil Nadu (Raman et al., 2003). Boer local is a crossbred goat evolved by Post Graduate Research Institute in Animal Sciences unit of Tamil Nadu Veterinary and Animal Sciences University. The important genetic agents contributing the milk production are types of breed and ability for milk secretion by individual animals (Meena et al., 2019). Reports on histology, immunohistochemistry of Furstenberg's rosette region in cow was reported by many authors. But, literature about Furstenberg's rosette of small ruminants such as sheep and goat is scarce. Hence, the present study was conducted to explore the Furstenberg's rosette in Madras Red ewes and Boer local she-goats.

How to cite this article: Senthilkumar, S., Kannan, T.A., Ramesh, G. and Sumathi, D. (2020). Histological and immunohistochemical studies of Furstenberg's rosette in sheep and goat. J. Anim. Res., 10(1): 123-126. 


\section{MATERIALS AND METHODS}

The present study was conducted in the Department of Veterinary Anatomy, Madras Veterinary College, Chennai. Teat samples were collected from apparently healthy, adult Madras Red ewes and Boer local she-goats ( $n=6$ each) immediately after the slaughter from corporation slaughter house, Chennai. Fixatives such as 10 per cent neutral buffered formalin (NBF) and bouin's fluid was used for sample fixation (Chaurasia et al., 2019). Tissues were processed by alcohol-xylene schedule and paraffin blocks were made (Luna, 1968). Then 5-6 $\mu \mathrm{m}$ thickness sections were cut by rotary microtome and stained by Haematoxylin and Eosin (H\&E) method for the routine histological study (Bancroft and Gamble, 2003), Masson's trichrome method for collagen and muscle fibers (Luna, 1968) and Verhoff's method for elastic fibers (Luna, 1968).

\section{Immunohistochemistry staining protocol}

$3 \mu \mathrm{m}$ paraffin sections were cut and mounted on charged slides and incubated at $60-70{ }^{\circ} \mathrm{C}$ for 30 minutes. The sections were deparaffinized by two changes in xylene, dehydrated in absolute alcohol (two changes) and washed twice in distilled water. Heat mediated antigen retrieval was done using TRIS-EDTA buffer ( $\mathrm{pH} 8.5$ - 9.0). Then the sections were washed twice in distilled water for two minutes. Blocking of endogenous peroxidase was done with 3 per cent hydrogen peroxide for ten minutes. Then the sections were incubated in CD3 (ready to use) primary antibody in a moist chamber for one hour. Polyexcel HRP (ready to use) secondary antibody was added and incubated for 12 minutes and sections were washed three times in PBS. Diaminobenzidine (DAB) chromogen solution (1ml DAB buffer +1 drop DAB chromogen) was added and kept for two to five minutes and washed in distilled water. Gill's haematoxylin was used to counter stained the sections for one minute. Bluing the sections was done with running tap water for five minutes. Finally, sections were dehydrated through graded series of alcohol, cleared in xylene and mounted in synthetic mountant (Senthilkumar et al., 2019). Microscopic images of stained slides were captured using the Leica microscope (CH9345 Heer brugg).

\section{RESULTS AND DISCUSSION}

In both Madras Red ewes and Boer local she-goats, the portion situated between the teat cistern and teat canal showed the presence of a modified structure called Furstenberg's rosette. The structure was made of mucosa thrown into longitudinal folds. Under lower magnification, cross-section of teat revealed the mucosal folds occluded the teat canal in a petal-like fashion or rosette of a flower. There were about 11-13 folds observed (Fig. 1 and 2).

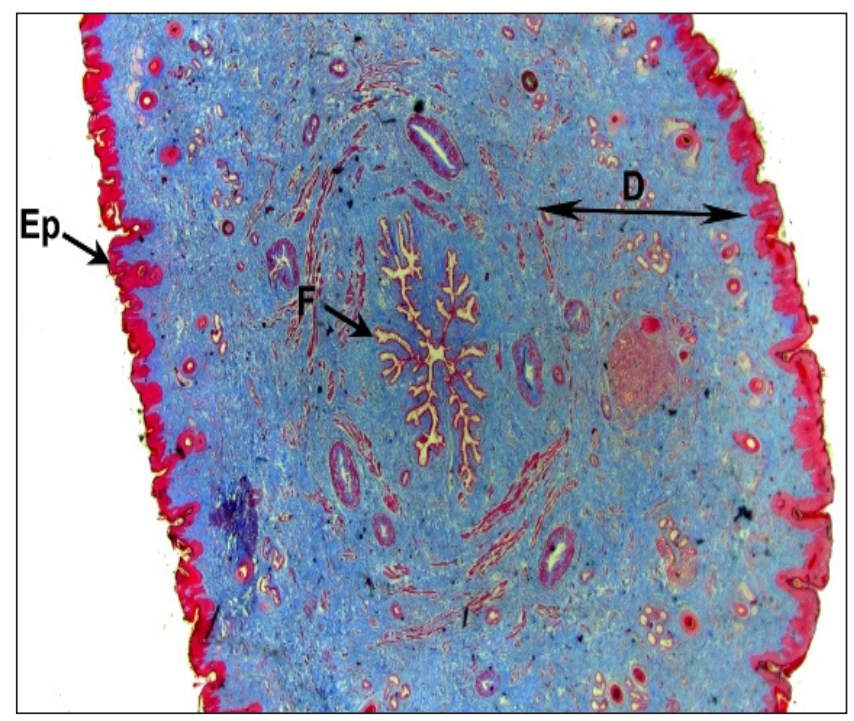

Fig. 1: Photomicrograph of the cross section of teat Boer graded local goat showing (D) Dermis, (Ep) Epidermis, (FR) Furstenberg's rosette Masson's trichrome $\times 12.5$

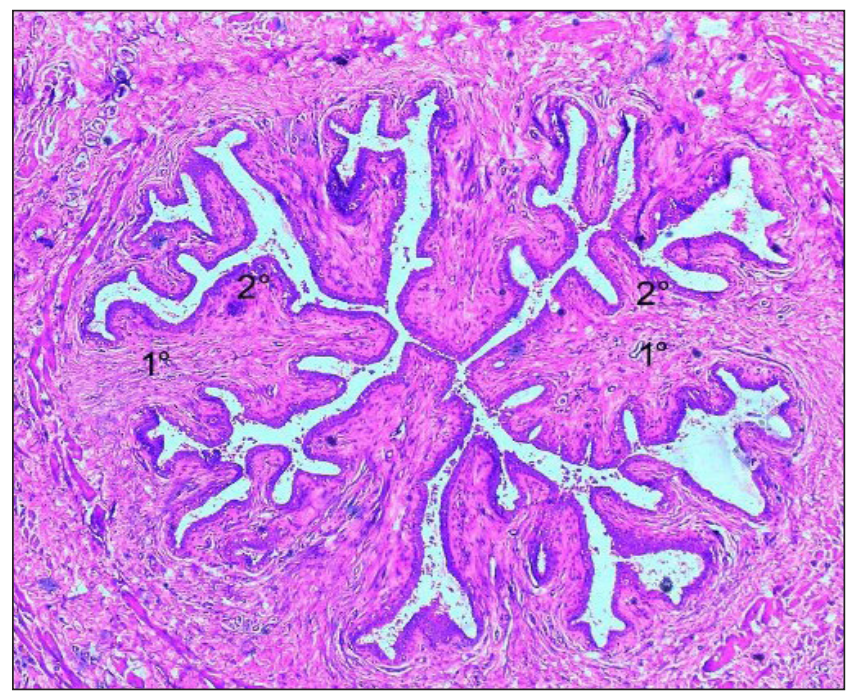

Fig. 2: Photomicrograph of the Furstenberg's rosette of Madras Red ewe showing mucosal $\left(1^{\circ}\right)$ Primary folds, $\left(2^{\circ}\right)$ Secondary folds $H \& E \times 50$ 
The folds were named according to their position by primary and secondary folds. These folds were projected into the lumen. A similar observation was made by Ganga Naik (2015) in cows. Avdic et al. (2015) indicated the significance of Furstenberg's rosette position in cows, who reported that irregular position leads to incomplete closure of teat canal. Teat cistern mucosa was lined by bilayered cuboidal epithelium with vacuolated cytoplasm (Fig. 3).

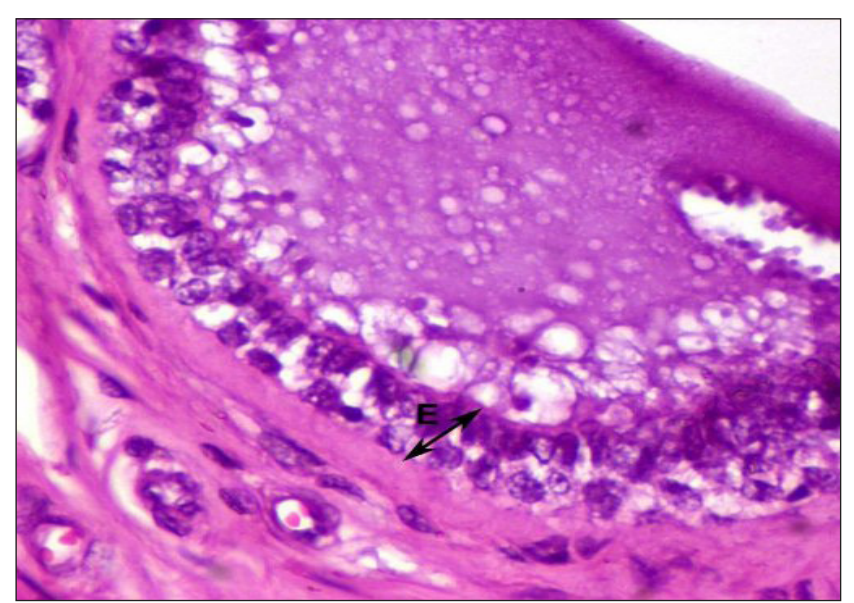

Fig. 3: Photomicrograph of the Furstenberg's rosette of Boer local goat showing lining epithelium (E) H\&E $\times 400$

Furstenberg's rosette was lined by a bi-layered cuboidal epithelium. Mucosa below the rosette was the teat canal and it is lined by a stratified squamous keratinized epithelium. Nickerson and Akers (2011) Nigam and Tyagi (1971) reported that the teat/streak canal was lined by a stratified squamous keratinized epithelium in cows and buffalos respectively. Lamina propria was comprised connective tissue made up of collagen, elastic fibres (Fig. 4) and blood vessels.

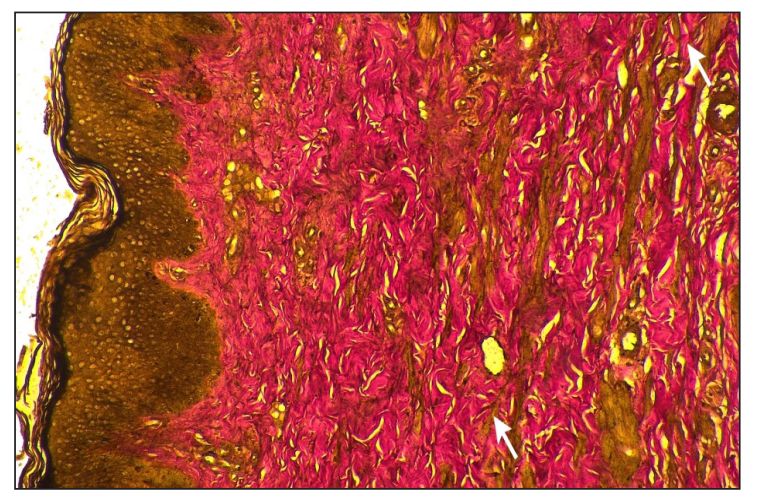

Fig. 4: Photomicrograph of the Furstenberg's rosette region of Boer local she-goat showing elastic fibres (arrows) Verhoff's method $\times 400$
Longitudinal and circular smooth muscle bundles were located surrounding the Furstenberg's rosette. In addition, a sub-epithelial layer of Furstenberg's rosette showed the presence of large number of lymphocytes (Fig. 5), plasma cells, polymorphonuclear leukocytes and macrophages. This is in total agreement with the findings of Avdic et al. (2015) in cows.

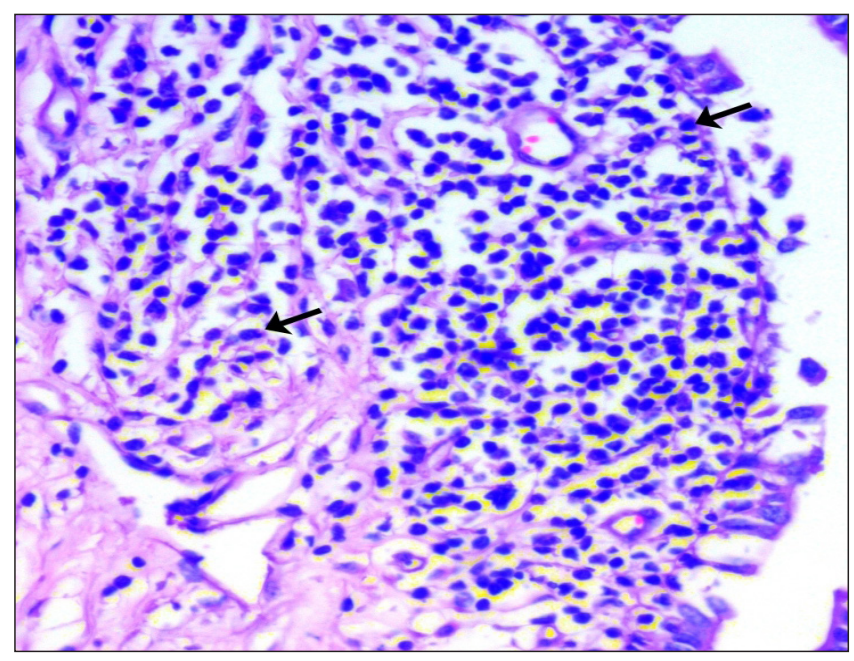

Fig. 5: Photomicrograph of the Furstenberg's rosette region of Madras Red ewe showing the lymphoid aggregation containing large number of lymphocytes (arrows) H\&E $\times 400$

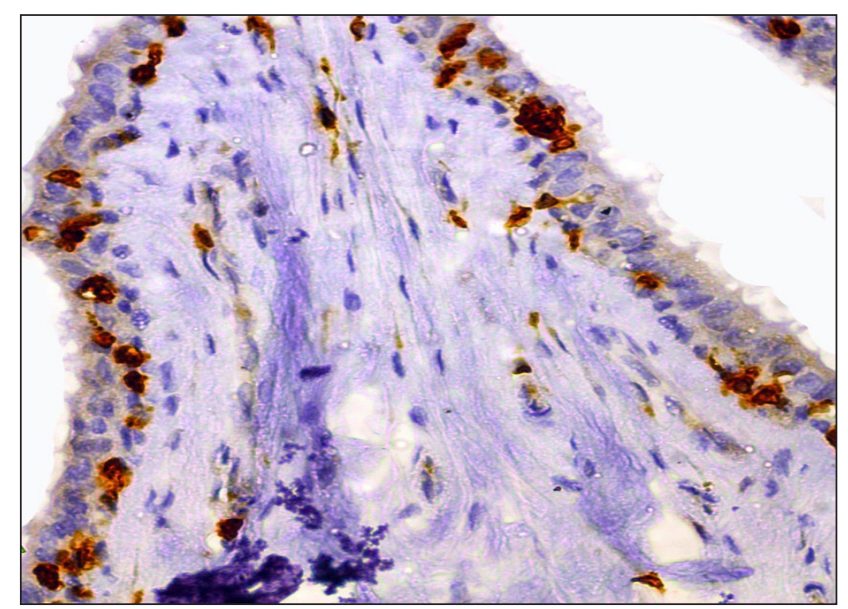

Fig. 6: Photomicrograph of the teat of Madras Red ewe showing $\mathrm{CD} 3+$ intraepithelial ' $\mathrm{T}$ ' lymphocytes (brown coloured cells) in fold of Furstenberg's rosette IHC (DAB) $\times 400$

Asti et al. (2011) observed in cows, that the presence of sub-epithelial lymphoid nodules in Furstenberg's rosette region indicative of greater capacity of tissue to establish response to invading microorganism in this part of the teat. 
He also mentioned that presence of lymphoid aggregations were indicative of previous exposure to infections. In both ewes and she-goats, immunohistochemical staining for CD3 positive ' $T$ ' lymphocytes revealed the presence of intraepithelial lymphocytes in Furstenberg's rosette (Fig. 6 and 7). CD3 positive ' $T$ ' lymphocytes were also localized within the lamina propria of mucosal folds involved in the formation of Furstenberg's rosette.

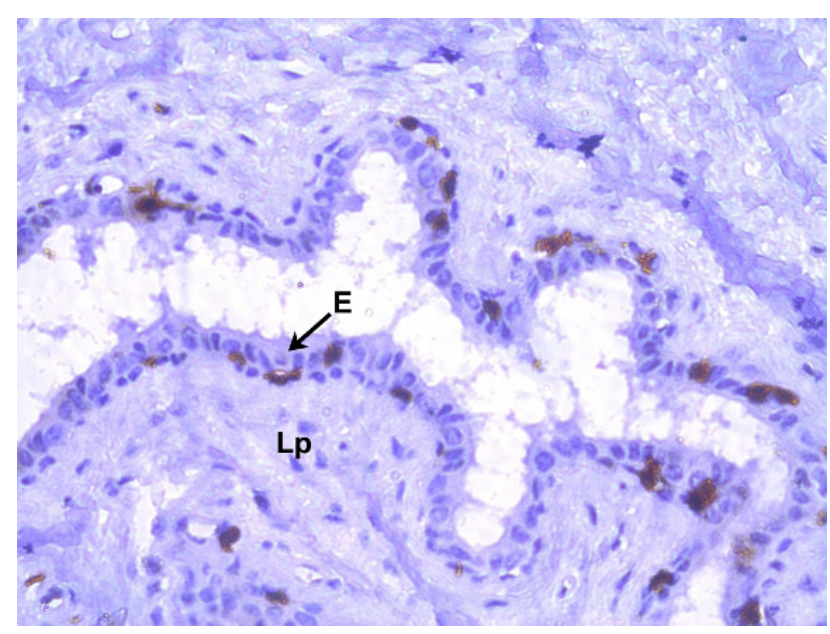

Fig. 7: Photomicrograph of the teat of Boer local she-goat showing CD3+ intraepithelial ' $\mathrm{T}$ 'lymphocytes (brown coloured cells) in fold of Furstenberg's rosette IHC (DAB) $\times 400$

Asti etal.(2011) observed in cow's teat that the lymphocytes showed numerical increase in Furstenberg's rosette region in normal teat tissues. lymphocytes make dense aggregates in a same appearance of lymphoid follicles. The author also opined that Furstenberg's rosette associated lymphoid tissue (FALT) was present in cow's teat. Specific response is formed locally against the antigens and this region had an important role in mucosal immune defense of teat end. A similar conclusion was drawn from the present study also.

\section{CONCLUSION}

Madras Red ewes and Boer local she-goats were the meat type breeds, mostly used for meat production in northern regions of Tamil Nadu. Even, in these animals, occurrence of mastitis and other teat infections were common. Hence, the study was conducted to explore the basic histological details and lymphoid aggregations in the area of Furstenberg's rosette. The study results will be used to correlate with the microscopic lesions in histopathological study in different disease conditions.

\section{Acknowledgements}

The author acknowledges the Dean, Madras Veterinary College for providing the necessary facilities to carry out the study.

\section{REFERENCES}

Asti, R.N., Kurtdede, N, Altunay, H, Alabay, B, Ozen, A and Bayraktaroglu, A.G. 2011. Histological and Immunohistochemical Studies on the Furstenberg's Rosette in Cows. Kafkas Univ. Vet. Fa Derg., 17(2): 223-228.

Avdic, R., Mrvic, V., Tandir, F., Hadziomerovic, N., Cuahija, V. and Bejdic, P. 2015. Macro and micro structure of Furstenberg rosette and teat canal. International Congress. "One World One Health - One Vision".

Bancroft, J.D. and Gamble, M. 2003. Theory and Practice of Histological Techniques. $5^{\text {th }}$ Edn., Churchill and Livingstone, New York, pp:593-620.

Chaurasia, D., Dalvi, R.S., Banubakode, S.B., Nety, S. Deshmukh, S.K. and Mandavi, S. 2019. Histological Study of Mammary Lobule on Pregnant, Lactation and Involution Stage in Murrah Buffalo. J. Anim. Res., 4(9): 01-03.

Ganga Naik, S. 2015. Gross and histomorphological studies on the mammary gland of Malnad gidda cows in Karnataka. Ph.D. Thesis, Karnataka Veterinary Animal and Fisheries Sciences University, Bidar, India.

Luna, 1968. Manual of Histological Staining Methods of the Armed Forces of institute of Pathology. $3^{\text {rd }}$ Edn., The Blackistone Div, Mcgrow-Hill Book Co, New York, pp. 9495.

Meena, G.L., Sharma, L., Burark, S.S. and Singh, H. (2019). Milk Production Function and Resource use Efficiency in Rajasthan. J. Anim. Res., 9(4): 01-06.

Nickerson, S.C. and Akers, R.M. 2011. Mammary gland, Encyclopedia of dairy sciences. $2^{\text {nd }}$ edition. 3: 328-337.

Nigam, J.M. and Tyagi, R.P.S. 1971. Pathology of teat obstruction in bovines. Hariyana Vet., 1: 63-67.

Senthilkumar, S., Kannan, T.A., Geethe Ramesh. and Sumathi, D. 2019. Histological and immunohistochemical observations of supramammary lymph node in sheep and goat. Int. J. Curr. Microbiol. Appl. Sci., 8(08): 74-82.

Smolenski, G.A. 2018. The bovine teat canal: Its role in pathogen recognition and defence of the mammary gland. Ph.D. Thesis, University of Waikato, New Zealand. 